\title{
Elevated caspase-1 activity and IL-1 $\beta$ expression are associated with the IPAF inflammasome in an experimental model of allergy
}

\author{
HAMID REZA NOURI ${ }^{1}$, AHMAD KARKHAH ${ }^{2}$, IRAJ MOHAMMADZADEH ${ }^{3}$ and MOJTABA SANKIAN $^{4}$ \\ ${ }^{1}$ Cellular and Molecular Biology Research Center, Health Research Institute; ${ }^{2}$ Student Research Committee, \\ School of Medicine, Babol University of Medical Sciences, Babol 47176; ${ }^{3}$ Non-communicable Pediatric Diseases \\ Research Center, Amirkola Children's Hospital, Amirkola 47317; ${ }^{4}$ Immunobiochemistry Lab, Immunology \\ Research Center, School of Medicine, Mashhad University of Medical Sciences, Mashhad 91735, Iran
}

Received August 29, 2015; Accepted January 27, 2016

DOI: $10.3892 / \mathrm{mmr} .2016 .4934$

\begin{abstract}
Previous studies have indicated that interleukin (IL)-1 $\beta$ has an important role in the development of allergic diseases. Therefore, the present study aimed to investigate the upstream pathway underlying IL- $1 \beta$ production in an experimental model of allergy. BALB/c mice (female, 6-8 weeks old) were sensitized to recombinant (r) Che a 2 by intraperitoneal injection of rChe a 2 adsorbed onto an alum gel suspension on days $0,7,14$ and 21 . In the control group, mice received an injection of $20 \mathrm{mM}$ phosphate-buffered saline absorbed onto alum via the same route. The allergic status of the mice was confirmed serologically by measuring allergen-specific immunoglobulin (Ig)E levels. The protein expression levels of IL-1 $\beta$ and the mRNA expression levels of inflammasome compartments were measured by enzyme-linked immunosorbent assay and semi-quantitative reverse transcription polymerase chain reaction, respectively. In addition, caspase-1 activity was determined by fluorometric assay. Sensitized mice exhibited significantly increased levels of specific $\operatorname{IgE}(\mathrm{P}<0.05)$. IL-1 $\beta$ production and caspase-1 activity were significantly higher in the sensitized mice compared with the control group. In addition, no significant differences were observed between the control and sensitized mice in the expression of genes associated with the inflammasome, including NLR family, pyrin domain containing 3; apoptosis-associated speck-like protein; and NLR family, apoptosis inhibitory protein 5 . However, IL-1 $\beta$ converting enzyme protease-activating factor
\end{abstract}

Correspondence to: Dr Mojtaba Sankian, Immunobiochemistry Lab, Immunology Research Center, School of Medicine, Mashhad University of Medical Sciences, Buali Street, Mashhad 91735, Iran E-mail: sankianm@mums.ac.ir

Abbreviations: ASC, apoptosis-associated speck-like protein; ELISA, enzyme-linked immunosorbent assay; IL-1 $\beta$, interleukin-1 $\beta$; IPAF, IL-1 $\beta$ converting enzyme protease-activating factor

Key words: allergy, caspase-1, IL-1 1 , inflammasome, IPAF
(IPAF) expression was significantly increased in sensitized mice compared with in the control group $(\mathrm{P}<0.05)$. These data indicate that caspase- 1 activation and IL- $1 \beta$ expression are associated with the IPAF inflammasome. Therefore, based on this association, the IPAF inflammasome may be considered for IL-1 $\beta$ production in the experimental model of allergy.

\section{Introduction}

An allergic response is characterized by an exaggerated immune reaction to certain antigens, including harmless environmental antigens from various sources, such as food and pollen. Approximately $25 \%$ of the population in developed countries suffers from immunoglobulin (Ig)E-mediated type I allergy $(1,2)$. Interleukin (IL)-1 $\beta$ has been identified as an important cytokine, which has a key role in the pathophysiology of allergic disorders (3). Furthermore, IL-1 $\beta$ has an essential role in the immune response to infectious agents (4).

IL-1 $\beta$ can be produced by immune cells, including blood monocytes, tissue macrophages and dendritic cells (5). IL-1 $\beta$ secretion is a two-step process: Firstly, interaction of Toll-like receptors (TLRs) with their ligands leads to an upregulation of pro-IL-1 $\beta$ gene transcription via nuclear factor- $\kappa \mathrm{B}(6)$. Secondly, caspase-1 activation results in the conversion of the immature pro-IL-1 $\beta$ into mature IL-1 $\beta$. It is well-established that caspase-1 activity is regulated by a cytosolic multi-protein complex known as the inflammasome (7). The inflammasome consists of a nucleotide-binding domain like receptor (NLR), one or more adaptor proteins, such as apoptosis-associated speck-like protein (ASC), and caspase-1 (8). Phylogenetic analysis of NLR family NACHT domains identified three distinct subfamilies: The nucleotide-binding oligomerization domain (NOD) subfamily [NOD1-2, NOD3/NLR family, CARD domain containing (NLRC)3, NOD4/NLRC5, NOD5/NLRX1, and class II, major histocompatibility complex, transactivator], the NLR family, pyrin domain containing (NLRP) subfamily (NLRP1-14, also called NALPs), and the IL-1 $\beta$ converting enzyme protease-activating factor (IPAF) subfamily, which consists of IPAF (also known as NLRC4) and NLR family, apoptosis inhibitory protein (NAIP) (9). 
The role of the inflammasome is essential in the maturation of IL-1 $\beta$. Elevated local or systemic levels of IL-1 $\beta$, associated with inappropriate inflammasome activity, have been reported in various diseases, particularly in allergic disorders (10-12). Furthermore, previous studies have reported that NLRP3, NLRP12 and absent in melanoma (AIM) 2 are involved in different models of allergy (13-15). In addition, NLRP3 has been introduced as an important inflammasome in contact hypersensitivity (16) and allergic airway diseases $(14,17)$. Arthur et al (15) demonstrated that the loss of NLRP12 protects against allergy in a mouse model of contact hypersensitivity. In addition, activation of AIM2 by DNA leads to production of IL-1 $\beta$ and IL-18 in patients with psoriasis (18).

At present, inflammasome activation in allergic diseases remains a controversial issue, and further studies are required to elucidate the exact role of inflammasomes in the context of allergy. Therefore, the present study was designed to investigate which inflammasome pathway is associated with caspase- 1 activation and IL- $1 \beta$ production in an animal model of allergy.

\section{Materials and methods}

Materials and mice. Recombinant (r)Che a 2, a major allergen in Chenopodium album pollen, was expressed and purified from Escherichia coli BL21 (DE3) by metal affinity chromatography, as described in our previous study (19). The alum gel suspension was purchased from Sigma-Aldrich (St. Louis, MO, USA). Biotinylated monoclonal rat anti-mouse IgE antibody (cat. no 1130-08) was purchased from SouthernBiotech, Inc. (Birmingham, AL, USA). Horseradish peroxidase (HRP)-conjugated streptavidin was obtained from Bio-Rad Laboratories, Inc. (Hercules, CA, USA). Female BALB/c mice (age, 6-8 weeks) were purchased from the Razi Vaccine and Serum Research Institute (Mashhad, Iran). The mice were housed at $21 \pm 2^{\circ} \mathrm{C}$ and a $12 \mathrm{~h}$ light-dark cycle was maintained. They were fed with standard rodent pellet and had free access to drinking water. Animals were maintained in the animal house according to the local guidelines for animal care, and experiments were approved by the Animal Ethics Committee of Babol University of Medical Sciences (Babol, Iran).

Induction and evaluation of allergy in BALB/c mice. Following 1 week of acclimation to the animal house environment, the sensitization protocol was conducted. Five BALB/c mice were sensitized by intraperitoneal (IP) injection of rChe a $2(5 \mu \mathrm{g})$ adsorbed onto $2 \mathrm{mg}$ alum $\left[\mathrm{Al}(\mathrm{OH})_{3}\right]$ gel suspension $(13 \mathrm{mg} / \mathrm{ml})$ on days $0,7,14$ and 21 . The mice in the control group $(n=5)$ received $20 \mathrm{mM}$ phosphate-buffered saline (PBS) absorbed onto $2 \mathrm{mg}$ alum gel suspension (IP), without rChe a 2, at the same time points (20). Subsequently, the sensitization procedure was continued with a 20 min exposure to an aerosol challenge of $1 \%$ rChe a 2 between days 26 and 28, using an Omron CX3 nebulizer (OMRON Healthcare Europe B.V., Hoofddorp, Netherlands). A total of 1 week following application of the final aerosol challenge, sensitization was complete. Subsequently, the mice were anesthetized using ketamine and xylazine ( $90 \mathrm{mg} / \mathrm{kg}$ and $10 \mathrm{mg} / \mathrm{kg}$ respectively, Sigma-Aldrich) and blood samples were collected through cardiac puncture. Next, the mice were scarified by cervical dislocation. In addition, weekly blood sampling via the retro-orbital plexus was conducted during sensitization, mice were anesthetized as aforementioned. The collected blood samples were left for $45 \mathrm{~min}$ at room temperature and then were centrifuged at $1,300 \mathrm{x} \mathrm{g}$ for $20 \mathrm{~min}$ at $4^{\circ} \mathrm{C}$. The obtained serum was transferred to microtubes and stored at $-80^{\circ} \mathrm{C}$.

Assessment of IgE and IL-1 $\beta$ levels. Specific IgE reactivity in serum samples was measured using an indirect enzyme-linked immunosorbent assay (ELISA). Briefly, microplate wells (Nunc MaxiSorp ${ }^{\mathrm{TM}}$; Thermo Fisher Scientific, Inc., Waltham, MA, USA) were coated with rChe a $2(20 \mu \mathrm{g} / \mathrm{ml})$ and were incubated at $4^{\circ} \mathrm{C}$ overnight. Blocking was performed using $2 \%$ bovine serum albumin (BSA; Sigma-Aldrich), and the microplate was washed with PBS with $0.05 \%$ Tween 20 (v/v). Mouse serum samples were diluted at 1:5 in 1\% BSA and were incubated in the microplate overnight at $4^{\circ} \mathrm{C}$. Subsequently, 1:5,000 biotinylated rat anti-mouse $\operatorname{IgE}$ antibody was added and incubated at $37^{\circ} \mathrm{C}$ for $1 \mathrm{~h}$. The microplate was then incubated with HRP-conjugated streptavidin for $1 \mathrm{~h}$. Finally, tetramethylbenzidine $/ \mathrm{H}_{2} \mathrm{O}_{2}$ was added to each well and color development was terminated with $3 \mathrm{M} \mathrm{HCl}$. Optical density was measured using an ELISA microplate reader (Stat Fax $^{\circledR} 2100$ Microplate Reader; Awareness Technology, Inc., Palm City, FL, USA). At the end of the experiment, lungs were removed and tissues were homogenized. Subsequently, IL-1 $\beta$ levels in the tissue lysates were measured using the RayBio ${ }^{\circledR}$ Mouse IL-1 beta ELISA kit (RayBiotech, Inc., Norcross, GA, USA) following the manufacturer's protocol.

RNA extraction and cDNA synthesis. Total RNA was isolated from the lung tissue homogenates using TriPure Isolation Reagent (Roche Diagnostics GmbH, Mannheim, Germany), according to the manufacturer's protocol. DNA contamination from $10 \mu \mathrm{g}$ RNA was removed with 2 U DNase I according to the manufacturer's protocol (Sigma-Aldrich). Total RNA was reverse transcribed using the Easy ${ }^{\mathrm{TM}}$ cDNA Reverse Transcription kit with oligo $(\mathrm{dT})_{16}$ and random hexamers as amplification primers (Pars Tous Biotechnology, Mashhad, Iran). Incubation at $25^{\circ} \mathrm{C}$ and $50^{\circ} \mathrm{C}$ was performed for 10 and $60 \mathrm{~min}$, respectively. Finally, the reaction was stopped by heating to $70^{\circ} \mathrm{C}$ for $10 \mathrm{~min}$.

Semi-quantitative reverse transcription polymerase chain reaction ( $R T-P C R)$. Specific oligonucleotide primers for the detection of genes involved in the inflammasome pathway, including NLRP3, ASC, IPAF and NAIP5, were designed by Primer Premier 5 software (PREMIER Biosoft, Palo Alto, CA, USA), according to data deposited on the Ensembl database (http://www.ensembl.org). Primer sequences are listed in Table I. Semi-quantitative RT-PCR was performed using the specific primers (Bioneer Corporation Daejeon, South Korea). The total reaction volume was $20 \mu \mathrm{l}$, containing $2 \mu \mathrm{l}$ cDNA, $12.5 \mathrm{pmol}$ of each primer, $1.5 \mathrm{Mm}$ of $\mathrm{MgCl}_{2}, 125 \mu \mathrm{M}$ dNTPs, $2 \mu 110 \mathrm{x}$ reaction buffer, and $2.0 \mathrm{U}$ of Taq polymerase (Bioneer Corporation). The cycling conditions were as follows: Initial denaturation at $95^{\circ} \mathrm{C}$ for $5 \mathrm{~min}$, then 34 cycles of denaturation at $95^{\circ} \mathrm{C}$ for $30 \mathrm{sec}$, annealing temperatures for all genes were at $59^{\circ} \mathrm{C}$ for $45 \mathrm{sec}$, extension for $45 \mathrm{sec}$ at $72^{\circ} \mathrm{C}$ and the final extension for $5 \mathrm{~min}$ at $72^{\circ} \mathrm{C}$. The PCR was performed using a 
Table I. Primer sequences used to evaluate the gene expression of inflammasome pathway-associated components.

Genes

Primers

Product

ASC

F: GCAACTGCGAGAAGGCTATG

NALP3

R: AAGCATCCAGCACTCCGTC

IPAF

F: GCTAAGAAGGACCAGCCAGAGT

R: GAACCTGCTTCTCACATGTCGT

NAIP5

F: TTACTGTGAGCCCTTGGAGCA

R: TGCCAGACTCGCCTTCAATC

F: TTCACATCGAGAAGTTATCCATCCA

R: AGCCTGGGCAAACTTTTCTGAC

HPRT

F: CGTCGTGATTAGCGATGATGAAC

R: TCACTAATGACACAAACGTGATTC

size (bp)

\begin{abstract}
F, forward; R, reverse; ASC, apoptosis-associated speck-like protein; NALP3, NLR family, pyrin domain containing 3; IPAF, interleukin-1 $\beta$ converting enzyme protease activating factor; NAIP5, NLR family, apoptosis inhibitory protein 5; HPRT, hypoxanthine phosphoribosyl transferase.
\end{abstract}

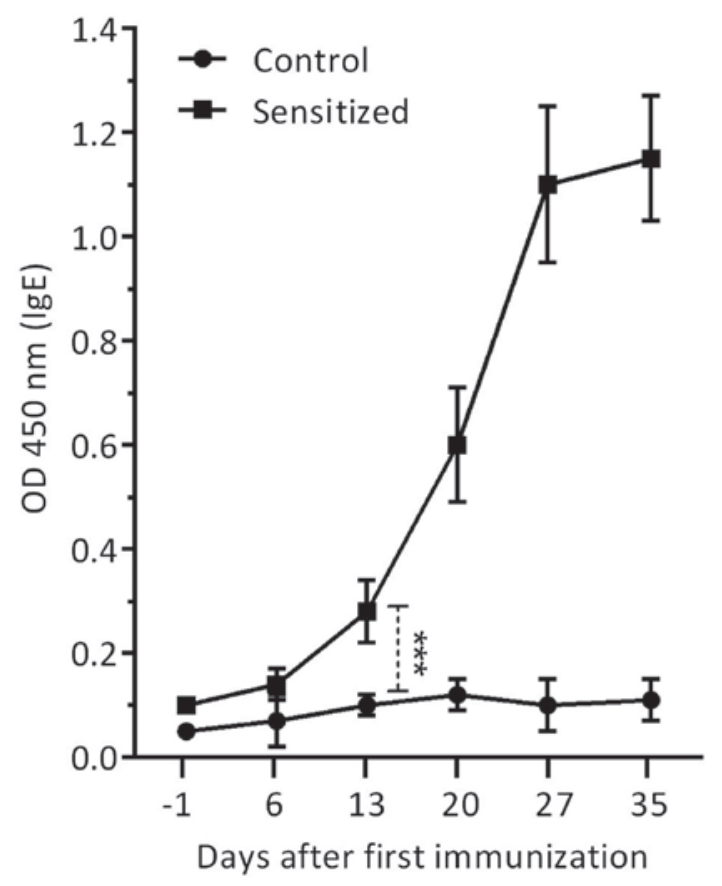

Figure 1. Time course of specific immunoglobulin (Ig)E levels during sensitization. Specific IgE levels were significantly increased in the sensitized mice from day 13. IgE titers were determined by enzyme-linked immunosorbent assay and are presented as optical density (OD) measured at $450 \mathrm{~nm}$. Results are presented as the mean \pm standard deviation. ${ }^{* * *} \mathrm{P}<0.001$, analyzed using Student's t-test.

peqSTAR 2X Thermocycler (Peqlab Biotechnologie GmbH, Erlangen, Germany). Subsequently, expression levels of the genes of interest were normalized to hypoxanthine phosphoribosyl transferase (HPRT) expression, which was used as an internal control. PCR products were electrophoresed on $2 \%$ agarose gels, and the subsequent bands were visualized using ethidium bromide (SinaClon, Tehran, Iran) staining and were documented using G:BOX (XT4; Syngene UK, Cambridge,

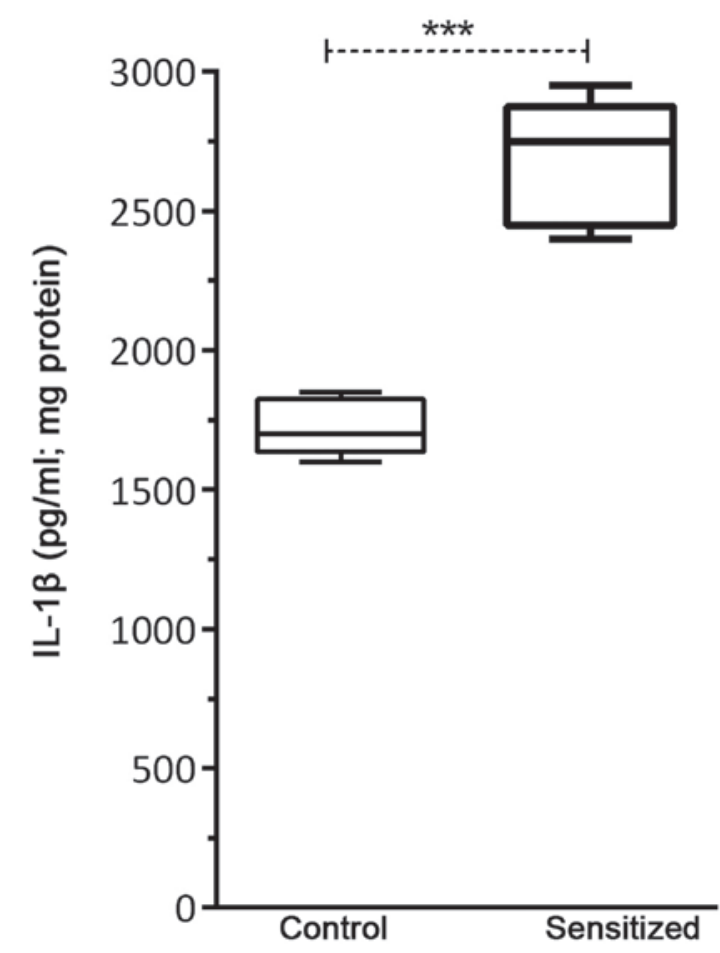

Figure 2. Interleukin (IL)-1 $\beta$ production in sensitized mice. IL-1 $\beta$ production was evaluated by enzyme-linked immunosorbent assay, and is expressed per $1 \mathrm{mg}$ of total protein obtained from lung tissue lysates. Data are presented as the median \pm interquartile range. ${ }^{* * * *} \mathrm{P}<0.001$, analyzed using Student's t-test.

UK). The intensity of the obtained bands was determined using ImageJ software (version 1.49; National Institutes of Health, Bethesda, MD, USA).

Caspase-1 activity assay. Mouse lung tissue was homogenized in lysis buffer (BioVision, Inc., Milpitas, CA, USA) using a homogenizer. Subsequently, homogenated tissue was centrifuged at $10,000 \times \mathrm{g}$ for $10 \mathrm{~min}$ in order to obtain the 
A
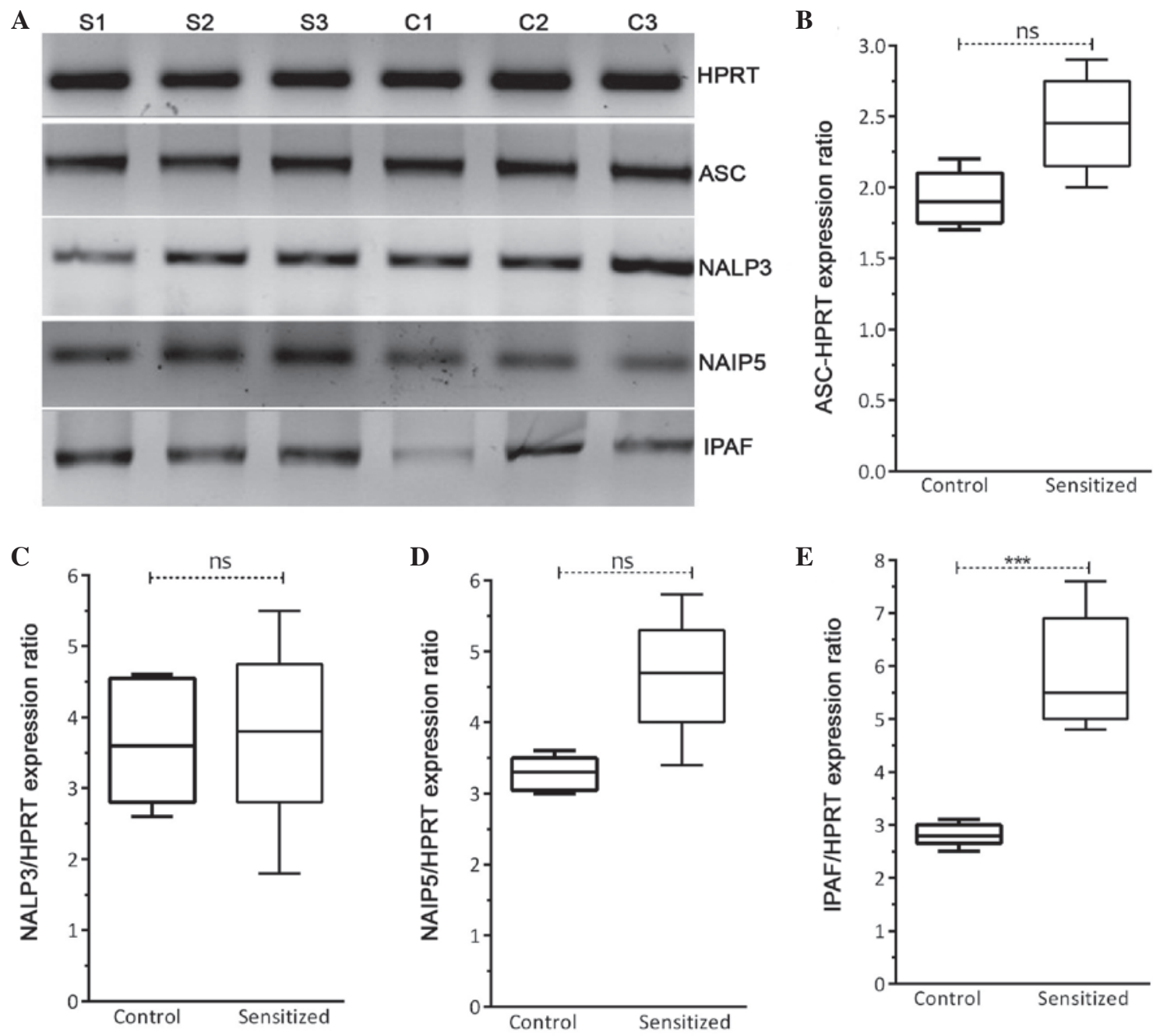

Figure 3. Expression of inflammasome-associated genes. (A) Reverse transcription polymerase chain reaction for the detection of components of the inflammasome pathway, including apoptosis-associated speck-like protein (ASC), NLR family, pyrin domain containing 3 (NALP3), NLR family, apoptosis inhibitory protein 5 (NAIP5) and interleukin-1 $\beta$ converting enzyme protease activating factor (IPAF). The gel represents the expression of three of the five samples in each group (S, sensitized; C, control). Relative mRNA expression levels (five samples in each group) of (B) ASC, (C) NALP3, (D) NAIP5 and (E) IPAF following normalization to hypoxanthine phosphoribosyl transferase (HPRT). Data are presented as the median \pm interquartile range. ${ }^{* * *} \mathrm{P}<0.001$, analyzed using Student's t-test. ns, not significant $(\mathrm{P}>0.05)$.

supernatant. Protein concentration in the supernatant was determined according to a previously described method for Bradford assay (21). The protein concentration was $1.7 \mathrm{mg}$ per $100 \mathrm{mg}$ of tissue. Caspase-1 activity was assessed using a Caspase-1 Fluorometric Assay kit (BioVision Inc.). The assay was based on detection of the cleavage of substrate YVAD-7-amino-4-trifluoromethyl coumarin (AFC). Briefly, YVAD-AFC emits blue light, whereas upon cleavage of the substrate by caspase-1, free AFC emits a yellow-green fluorescence, which was quantified using a spectrofluorometer (FP-6200; Jasco, Inc., Easton, MD, USA). Comparison of the fluorescence of AFC from a treated sample with an untreated control sample allows the determination of fold increase in caspase-1 activity.

Statistical analysis. All data are presented as the mean \pm standard deviation of the combined experiments. Each experiment was repeated at least twice. Comparisons between the control and sensitized mice were evaluated using Student's t-test for independent means. To quantify the degree to which two variables were related in sensitized mice, Pearson's correlation test was used. $\mathrm{P}<0.05$ was considered to indicate a statistically significant difference between values. All data were analyzed using GraphPad Prism ${ }^{\circledR} 6.0$ package for Windows (GraphPad Software Inc., La Jolla, CA, USA).

\section{Results}

Induction of specific IgE in sensitized mice. The allergic condition was confirmed serologically by the presence of specific IgE to rChe a 2 in the sensitized mice compared with in the control mice. Administration of rChe a 2 plus alum adjuvant induced high levels of specific $\operatorname{IgE}$ in the sera of sensitized mice, which was markedly increased $(\mathrm{P}=0.0001)$ on day 13 following initial immunization, and peaked on day 27 (Fig. 1). The increased IgE levels were maintained at the maximum level until termination of the experiment (day 35). No specific IgE levels were observed in the serum samples of the control group, which received PBS absorbed onto an alum gel suspension. 

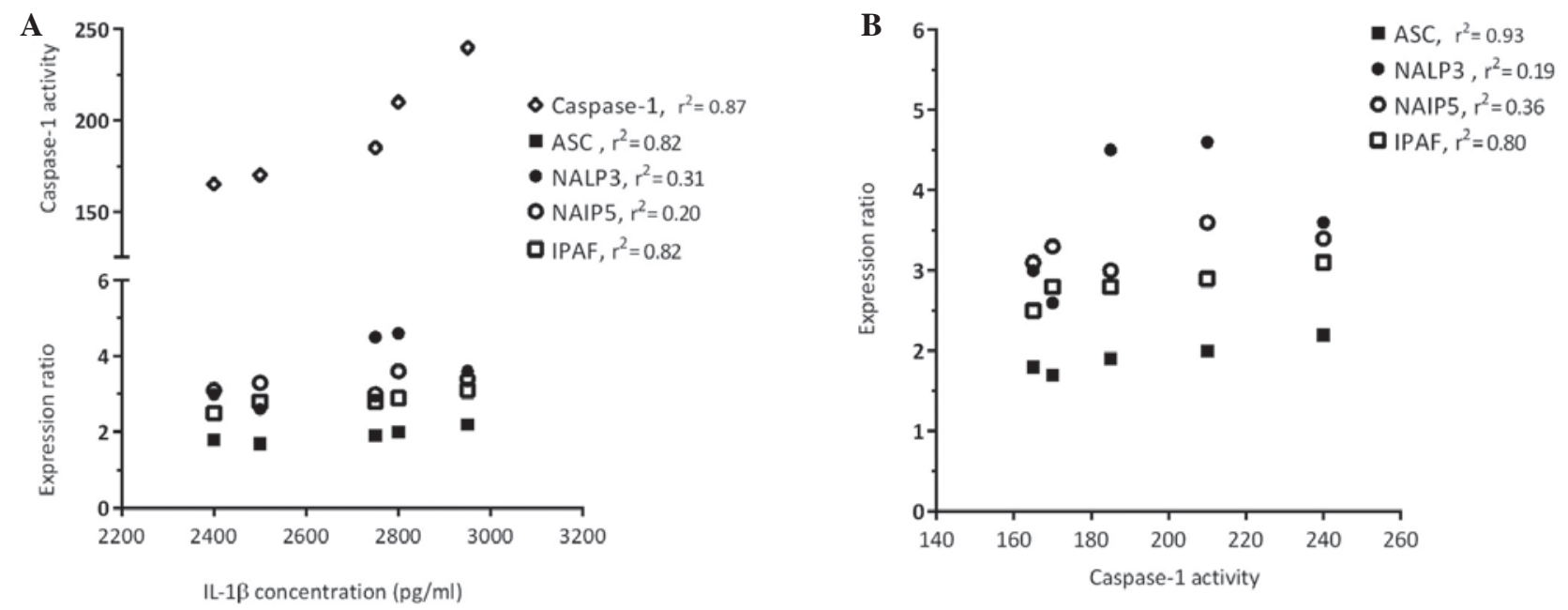

Figure 4. (A) Association between interleukin (IL)-1 $\beta$ concentration and caspase-1 activity or inflammasome-associated gene expression. (B) Association between caspase-1 activity and relative expression of apoptosis-associated speck-like protein (ASC), NLR family, pyrin domain containing 3 (NALP3), NLR family, apoptosis inhibitory protein 5 (NAIP5) and interleukin- $1 \beta$ converting enzyme protease activating factor (IPAF). IPAF expression was associated with IL-1 $\beta\left(r^{2}=0.82, P=0.03\right)$ and caspase-1 activity production and caspase- $1\left(r^{2}=0.80, P=0.04\right) . r^{2}$ indicates correlation coefficient.

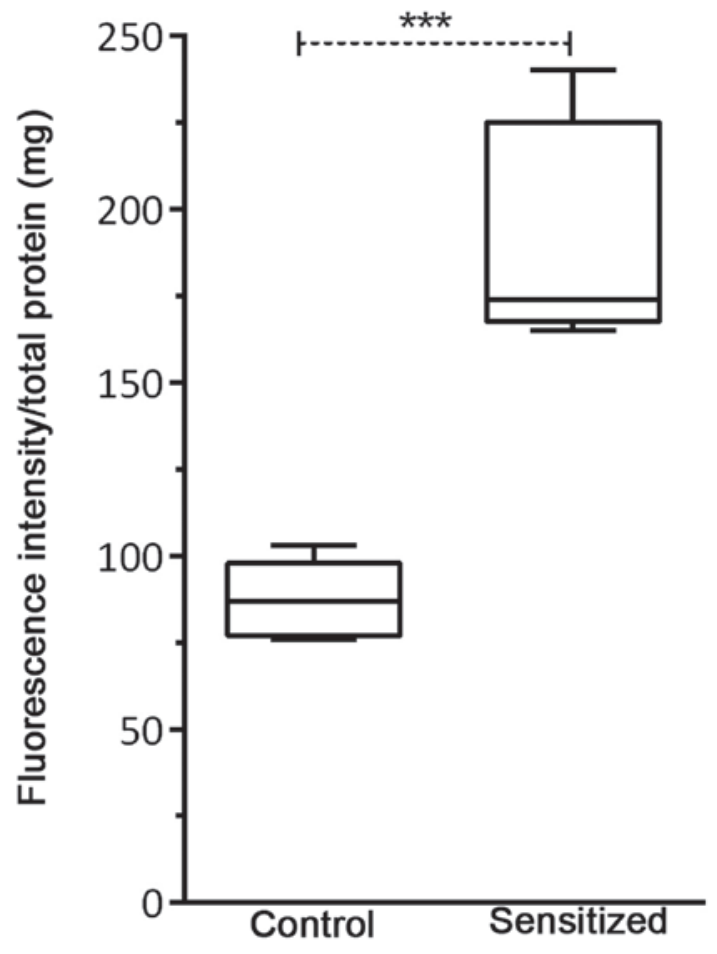

Figure 5. Caspase-1 activity following allergy induction. Caspase-1 activity was significantly increased in sensitized mice compared with in control mice. Data are presented as the median \pm interquartile range. ${ }^{* * * *} \mathrm{P}<0.001$, analyzed using Student's t-test.

$I L-1 \beta$ production following sensitization. As shown in Fig. 2, IL-1 $\beta$ levels were significantly increased in the sensitized mice, as compared with in the control mice $(\mathrm{P}<0.001)$. It should be noted that IL-1 $\beta$ levels were calculated per $1 \mathrm{mg}$ of total protein obtained from tissue homogenates.

Significant association of IPAF expression and IL-1 $\beta$ production in sensitized mice. In the present study, the expression levels of genes associated with inflammasome activation were evaluated by semi-quantitative RT-PCR in the sensitized and control mice. The results of an RT-PCR assay for detection of the following components of the inflammasome pathway are shown in Fig. 3: ASC, NALP3, NAIP5 and IPAF. The relative expression levels of ASC, NALP3 and NAIP5 were normalized to HPRT expression, and no significant differences were detected between the groups (Fig. 3A-D). As shown in Fig. 4, analysis of the correlation between NALP3 and NAIP5 expression and IL-1 $\beta$ concentration (Fig. 4A) and caspase-1 activity (Fig. 4B) demonstrated that these genes did not exert effects on IL-1 $\beta$ production or caspase-1 activation following allergy induction in sensitized mice. As shown in Fig. 3E, the mRNA expression levels of IPAF were significantly higher $(\mathrm{P}=0.0003)$ in the sensitized mice compared with in the control mice. In addition, results obtained from the correlation analysis (Fig. 4) indicated that the high expression of IPAF in the lung homogenates of sensitized mice was associated with increased IL-1 $\beta$ production $(\mathrm{P}=0.03)$ and caspase-1 activity $(\mathrm{P}=0.04)$.

Caspase-1 activity is associated with allergy induction. Mean adjusted caspase-1 activity per $1 \mathrm{mg}$ of total protein obtained from lung tissue homogenates was determined by fluorometric assay (Fig. 5). A significant increase in caspase-1 activity $(\mathrm{P}=0.001)$ was observed in the sensitized mice compared with the control mice, following an allergen challenge.

\section{Discussion}

It has been well-established that IL-1 is a critical mediator of the inflammatory process in various diseases, including asthma and other allergic disorders $(22,23)$. Allergy or hypersensitivity is one of the most important IL-1 $\beta$-associated disorders, which affects many people in developed countries (3). Recognition of IL- $1 \beta$, and its secretion pathway via the inflammasome, may represent a potential target for the development of novel specific drugs for the treatment of allergy-related disorders $(24,25)$.

Recently, the mechanisms underlying injury or allergen-induced inflammasome activation and TLR4-dependent allergic inflammation have been 
investigated $(10,26)$. Injury or allergen exposure may lead to the formation of specific inflammasome pathways via caspase- 1 activation, thus resulting in IL-1 $\beta$ release $(9,10,27)$. Furthermore, animal studies have identified IL-1 $\beta$ as a key molecule responsible for induction of inflammatory pathways in experimental models of allergy $(3,28,29)$.

The present study investigated the production of IL-1 $\beta$ in an experimental model of allergy, and considered the specific inflammasome pathway that contributes to caspase-1 activation. Previous studies have demonstrated that components of the NLRP3 inflammasome contribute to allergic airway inflammation via the regulation of IL-1 $\beta(17,30)$. However, other publications have reported conflicting results (31). The results of the present study detected no significant differences in NALP3 and NAIP5 expression between the control and sensitized mice. Similar to the present study, Kool et al (31) reported that NLRP3 does not significantly contribute to allergic airway inflammation in mice. In addition, Allen et al (14) indicated that NLRP3 does not significantly contribute to the development of ovalbumin- or house dust mite-mediated allergic airway inflammation in mice. However, in contrast to the present results, it has been indicated that NLRP3 inflammasome activation leads to IL-1 production, and is important for the induction of a Th2 inflammatory allergic response (17). The results of the present study suggested that the NALP3 inflammasome was consistently activated in the control and sensitized groups. This activation may be related to the use of an alum adjuvant in the present study, this may be controlled for in the future by adding more treatment groups that have been sensitized to the allergen by various methods. Other studies have confirmed that the properties of alum adjuvant can act as a danger signal and can trigger inflammasome activation via NALP3 $(30,32)$.

Notably, the present study not only detected significantly increased expression levels of IPAF in sensitized mice compared with in control mice, but also detected increased caspase- 1 activation and IL- $1 \beta$ production in the lungs of sensitized mice. Based on these obtained results, it may be hypothesized that high levels of caspase-1 activity in sensitized mice may be affected by a marked change in IPAF expression. In addition, caspase- 1 activation may lead to the processing and maturation of IL-1 $\beta$, thus resulting in allergic symptoms in the sensitized mice. In accordance with these results, a previous study reported that elevated expression of IPAF, alongside IL-1 $\beta$, is involved in the inflammation of patients with pemphigus vulgaris (33). In addition, Liu and Chan (34) revealed that palmitate was able to induce the production of IL-1 $\beta$ via activation of the IPAF-ASC inflammasome in primary astrocytes.

Recent studies have demonstrated that specific pathogen-associated molecular patterns and danger-associated molecular patterns may activate the IPAF inflammasome, which results in recruitment of ASC and procaspase-1. Procaspase- 1 is cleaved into active caspase-1, which contributes to the processing of pro-IL-1 $\beta$ into its biologically active form, IL-1 $\beta(9,35)$. The IPAF inflammasome is a novel member of the NLR family, which is a well-known sensor for bacterial flagellin during infection with Legionella pneumophila, Salmonella and Pseudomonas, and has been coupled with pro-IL-1 $\beta$ processing. Furthermore, dysregulated IPAF expression has an essential role in the pathogenesis of several autoimmune and inflammatory diseases, including pemphigus vulgaris, Kawasaki and atopic dermatitis $(36,37)$. Composition of the IPAF inflammasome requires ASC and pro-caspase-1. Compared with other inflammasomes, IPAF is able to activate caspase-1 in an ASC-dependent or -independent manner (38). However, the exact composition of IPAF is not clear in allergy. In an attempt to improve understanding regarding the composition of IPAF inflammasomes, Gutierrez et al (39) demonstrated that IPAF is upregulated by tumor necrosis factor- $\alpha$ in human leukemia cells. Therefore, our next step is to identify the main stimulus of IPAF in the context of allergy.

The results of the present study indicated that caspase-1 activation and IL-1 $\beta$ expression are associated with the IPAF inflammasome. Therefore, based on this association, the IPAF inflammasome may be considered to have a crucial role in experimental models of allergy. However, further experiments are required to elucidate the exact role of the IPAF inflammasome in allergic diseases, which may be useful for the identification of a novel approach for the treatment and management of allergic disorders.

In conclusion, although further analysis is required to clarify the role of IPAF in allergy, the present study demonstrated that IPAF inflammasome expression is associated with caspase- 1 activity and IL-1 $\beta$ production in an experimental model of allergy.

\section{Acknowledgements}

The present study was supported by the Research Administration Department of Babol University of Medical Sciences (grant no. 9339224). The authors would like to thank Dr Evangeline Foronda in the Research Administration Department of Babol University of Medical Sciences for editing the manuscript.

\section{References}

1. Venarske D and deShazo RD: Molecular mechanisms of allergic disease. South Med J 96: 1049-1054, 2003.

2. Broide DH: Molecular and cellular mechanisms of allergic disease. J Allergy Clin Immunol 108 (Suppl 2): S65-S71, 2001.

3. Krause K, Metz M, Makris M, Zuberbier T and Maurer M: The role of interleukin-1 in allergy-related disorders. Curr Opin Allergy Clin Immunol 12: 477-484, 2012.

4. Hsu LC, Ali SR, McGillivray S, Tseng PH, Mariathasan S, Humke EW, Eckmann L, Powell JJ, Nizet V, Dixit VM and Karin M: A NOD2-NALP1 complex mediates caspase-1-dependent IL-1beta secretion in response to Bacillus anthracis infection and muramyl dipeptide. Proc Natl Acad Sci USA 105: 7803-7808, 2008.

5. Dinarello CA: Immunological and inflammatory functions of the interleukin-1 family. Annu Rev Immunol 27: 519-550, 2009.

6. Guarda G, Zenger M, Yazdi AS, Schroder K, Ferrero I, Menu P, Tardivel A, Mattmann C and Tschopp J: Differential expression of NLRP3 among hematopoietic cells. J Immunol 186: 2529-2534, 2011.

7. Martinon F, Burns K and Tschopp J: The inflammasome: A molecular platform triggering activation of inflammatory caspases and processing of proIL-beta. Mol Cell 10: 417-426, 2002.

8. Schroder K and Tschopp J: The inflammasomes. Cell 140: 821-832, 2010.

9. Latz E: The inflammasomes: Mechanisms of activation and function. Curr Opin Immunol 22: 28-33, 2010.

10. Masters SL: Specific inflammasomes in complex diseases. Clin Immunol 147: 223-228, 2013. 
11. Brusselle GG, Provoost S, Bracke KR, Kuchmiy A and Lamkanfi M: Inflammasomes in respiratory disease: From bench to bedside. Chest 145: 1121-1133, 2014.

12. Jamilloux Y, Sève P and Henry T: Inflammasomes in human diseases. Rev Med Interne 35: 730-741, 2014 (In French).

13. Dombrowski Y, Peric M, Koglin S, Kaymakanov N, Schmezer V, Reinholz M, Ruzicka T and Schauber J: Honey bee (Apis mellifera) venom induces AIM2 inflammasome activation in human keratinocytes. Allergy 67: 1400-1407, 2012.

14. Allen IC, Jania CM, Wilson JE, Tekeppe EM, Hua X, Brickey WJ, Kwan M, Koller BH, Tilley SL and Ting JP: Analysis of NLRP3 in the development of allergic airway disease in mice. J Immunol 188: 2884-2893, 2012.

15. Arthur JC, Lich JD, Ye Z, Allen IC, Gris D, Wilson JE, Schneider M, Roney KE, O'Connor BP, Moore CB, et al: Cutting edge: NLRP12 controls dendritic and myeloid cell migration to affect contact hypersensitivity. J Immunol 185: 4515-4519, 2010.

16. Watanabe H, Gaide O, Pétrilli V, Martinon F, Contassot E, Roques S, Kummer JA, Tschopp J and French LE: Activation of the IL-1beta-processing inflammasome is involved in contact hypersensitivity. J Invest Dermatol 127: 1956-1963, 2007.

17. Besnard AG, Guillou N, Tschopp J, Erard F, Couillin I, Iwakura Y, Quesniaux V, Ryffel B and Togbe D: NLRP3 inflammasome is required in murine asthma in the absence of aluminum adjuvant. Allergy 66: 1047-1057, 2011.

18. Dombrowski Y, Peric M, Koglin S, Kammerbauer C, Göss C, Anz D, Simanski M, Gläser R, Harder J, Hornung V, et al: Cytosolic DNA triggers inflammasome activation in keratinocytes in psoriatic lesions. Sci Transl Med 3: 82ra38, 2011.

19. Nouri HR, Sankian M, Vahedi F, Afsharzadeh D, Rouzbeh L, Moghadam M and Varasteh A: Diagnosis of Chenopodium album allergy with a cocktail of recombinant allergens as a tool for component-resolved diagnosis. Mol Biol Rep 39: 3169-3178, 2012.

20. Nouri HR, Sankian M, Afsharzadeh D and Varasteh A: Immunotherapy with a recombinant hybrid molecule alleviates allergic responses more efficiently than an allergenic cocktail or pollen extract in a model of Chenopodium album allergy. Int Arch Allergy Immunol 161: 325-332, 2013.

21. Bradford MM: A rapid and sensitive method for the quantitation of microgram quantities of protein utilizing the principle of protein-dye binding. Anal Biochem 72: 248-254, 1976.

22. Lane $T$ and Lachmann HJ: The emerging role of interleukin-1 $\beta$ in autoinflammatory diseases. Curr Allergy Asthma Rep 11: 361-368, 2011.

23. Sedimbi SK, Hägglöf T and Karlsson MC: IL-18 in inflammatory and autoimmune disease. Cell Mol Life Sci 70: 4795-4808, 2013.

24. López-Castejón G and Pelegrín P: Current status of inflammasome blockers as anti-inflammatory drugs. Expert Opin Investig Drugs 21: 995-1007, 2012.

25. Kontogiorgis CA and Hadjipavlou-Litina DJ: Non steroidal anti-inflammatory and anti-allergy agents. Curr Med Chem 9: 89-98, 2002 .
26. Fietta $P$ and Delsante G: The inflammasomes: The key regulators of inflammation. Riv Biol 102: 365-384, 2009.

27. Skeldon AM, Faraj M and Saleh M: Caspases and inflammasomes in metabolic inflammation. Immunol Cell Biol 92: 304-313, 2014.

28. Blom L and Poulsen LK: IL-1 family members IL-18 and IL-33 upregulate the inflammatory potential of differentiated human Th1 and Th2 cultures. J Immunol 189: 4331-4337, 2012.

29. Lukens JR, Gross JM and Kanneganti TD: IL-1 family cytokines trigger sterile inflammatory disease. Front Immunol 3: 315, 2012.

30. Eisenbarth SC, Colegio OR, O'Connor W, Sutterwala FS and Flavell RA: Crucial role for the Nalp3 inflammasome in the immunostimulatory properties of aluminium adjuvants. Nature 453: 1122-1126, 2008

31. Kool M, Willart MA, van Nimwegen M, Bergen I, Pouliot P, Virchow JC, Rogers N, Osorio F, Reis e Sousa C, Hammad H and Lambrecht BN: An unexpected role for uric acid as an inducer of $\mathrm{T}$ helper 2 cell immunity to inhaled antigens and inflammatory mediator of allergic asthma. Immunity 34 : 527-540, 2011

32. Kool M, Pétrilli V, De Smedt T, Rolaz A, Hammad H, van Nimwegen M, Bergen IM, Castillo R, Lambrecht BN and Tschopp J: Cutting edge: Alum adjuvant stimulates inflammatory dendritic cells through activation of the NALP3 inflammasome. J Immunol 181: 3755-3759, 2008.

33. Shamsabadi RM, Basafa S, Yarahmadi R, Goorani S, Khani M, Kamarehei $M$ and Hossein Kiani A: Elevated expression of NLRP1 and IPAF are related to oral pemphigus vulgaris pathogenesis. Inflammation 38: 205-208, 2015.

34. Liu L and Chan C: IPAF inflammasome is involved in interleukin- $1 \beta$ production from astrocytes, induced by palmitate; implications for Alzheimer's disease. Neurobiol Aging 35: 309-321, 2014.

35. Mariathasan S, Newton K, Monack DM, Vucic D, French DM, Lee WP, Roose-Girma M, Erickson S and Dixit VM: Differential activation of the inflammasome by caspase-1 adaptors ASC and Ipaf. Nature 430: 213-218, 2004.

36. AbdelazizDH,AmrKandAmerAO:Nlrc4/Ipaf/CLAN/CARD12: More than a flagellin sensor. Int J Biochem Cell Biol 42 789-791, 2010

37. Vinzing M, Eitel J, Lippmann J, Hocke AC, Zahlten J, Slevogt H, N'guessan PD, Günther S, Schmeck B, Hippenstiel S, et al: NAIP and Ipaf control Legionella pneumophila replication in human cells. J Immunol 180: 6808-6815, 2008.

38. Hu B, Elinav E, Huber S, Booth CJ, Strowig T, Jin C, Eisenbarth SC and Flavell RA: Inflammation-induced tumorigenesis in the colon is regulated by caspase-1 and NLRC4. Proc Natl Acad Sci USA 107: 21635-21640, 2010

39. Gutierrez O, Pipaon C and Fernandez-Luna JL: Ipaf is upregulated by tumor necrosis factor-alpha in human leukemia cells. FEBS Lett 568: 79-82, 2004. 